\title{
The Performance, Nutrient Digestibility, Aflatoxin B1 Residue, and Histopathological Changes of Broilers Exposed to Dietary Mycosorb
}

\author{
C. L. Nalle ${ }^{\mathrm{a}, *}$, M. A. J. Supit ${ }^{\mathrm{b}}$, A. H. Angi ${ }^{\mathrm{c}}$, \& N. S. Yuliani ${ }^{\mathrm{c}}$ \\ ${ }^{a}$ Feed Technology Study Program, Department of Animal Husbandry, State Polytechnic of Agriculture Kupang \\ ${ }^{\mathrm{b}}$ Animal Production Study Program, Department of Animal Husbandry, State Polytechnic of Agriculture Kupang \\ cAnimal Health Study Program, Department of Animal Husbandry, State Polytechnic of Agriculture Kupang \\ Jalan Prof. Herman Yohanes, Kelurahan Lasiana 85228, Kupang-Indonesia \\ *Corresponding author: nallecatootjie@gmail.com \\ (Received 10-06-2020; Revised 17-07-2020; Accepted 13-08-2020)
}

\begin{abstract}
Aflatoxin B1 (AFB1) is the most dangerous type of aflatoxin that can impair poultry productivity even in low concentrations. The harmful effects of AFB1 should be minimized. The present study was conducted to evaluate the performance, nutrient digestibility, AFB1 residue, and histopathological changes of broilers fed AFB1 diets supplemented with mycosorb. Two hundred-forty 1-day old broiler chicks were allocated randomly to 24 pens (10 birds/pen). The experimental design was a $4 \times 2$ factorial arrangement, with AFB1 level and yeast glucomannan (mycosorb) supplementation as the main factors. The treatment diets were control diet; control diet + mycosorb; AFB1 diets (10.36 ppb); AFB1 diets (10.36 ppb) + mycosorb; AFB1 diets (26.97 ppb); AFB1 diets (26.97 ppb) + mycosorb; AFB1 diets $(61.06 \mathrm{ppb})$; AFB1 diets $(61.06 \mathrm{ppb})+$ mycosorb. The results showed that there was no interaction effect was found between the level of AFB1 and mycosorb on the performance and nutrient digestibility. The level of AFB1 did not affect dry matter digestibility coefficient but affected $(p<0.05)$ crude fat digestibility coefficient of broilers. Except for proventriculus, level of AFB1 did not affect bird's gut size. AFB1 residue was not detected in the broiler tissues fed all diets. Mycosorb alone ameliorated $(\mathrm{p}<0.05)$ feed conversion ratio (FCR) of growing birds. The birds fed $61.06 \mathrm{ppb}$ AFB1 diets had darker liver than those fed similar diets added with mycosorb. The addition of mycosorb in AFB1 diets did not heal the hemorrhagic intestines of the birds. In conclusion, feeding low level of AFB1 diets added with mycosorb did not improve the bird's performance, nutrient digestibility, or gut health. Mycosorb alone improved feed efficiency of the experimental birds.
\end{abstract}

Keywords: aflatoxin; broiler; mycotoxin binder; performance; toxicological effect

\section{INTRODUCTION}

Aflatoxins are the secondary substance formed by Aspergillus flavus and Aspergillus parasiticus. There are four major compounds of aflatoxins which are aflatoxin B1 (AFB1), B2 (AFB2), G1 (AFG1), and G2 (AFG2), with AFB1 being the most hazardous and plentiful aflatoxin (Fouad et al., 2019; Carvajal-Moreno, 2015). The danger from AFB1 in poultry is associated with low productivity and a high susceptibility to diseases. The second dangerous type of aflatoxin is AFG1, followed by AFB2 and AFG2.

Aflatoxin B1 negatively influences several organs and tissues, with liver being the most targeted organ (Rotimi et al., 2019, 2017). The changes in morphology and histology of the gastrointestinal tract and immune organs (spleen, thymus, and bursa of fabricius), disturbance of nutrient digestibility, low egg quality, low meat quality, low productivity, and low reproductivity are the toxicological impacts of aflatoxins in bird (Kurniasih \& Prokoso, 2019; Sineque et al., 2017; Galarsa-Seeber et al., 2016; Peng et al., 2015; Marchioro et al. 2013; Yang et al., 2012; Kumar \& Balachandran, 2009). In a study by Solis-Cruz et al. (2019), it was observed that feeding a high amount of AFB1 in the diet changed the color of the skin of thigh muscle and footpad of birds. Saki et al. (2018) state that mycotoxin can cause oxidative damage to the cell lining of gastrointestinal tract and decreased cellular protein synthesis. The injury and irritation in the gastrointestinal tract as a result of oxidative damage in the cell membrane will decrease nutrient digestibility and absorption. The level of detrimental impacts caused by aflatoxins depends on the level of aflatoxins, duration of administration, and species of bird. The concentration of aflatoxin B1 (AFB1) that causes aflatoxicosis and impairs bird's productivity depends on the fungal strain and the susceptibility of bird's species (Fouad et al., 2019; Grenier \& Applegate, 2013). Furthermore, the authors report that the most susceptible species to AFB1 is duck, followed by the broiler chick. A meta-analysis conducted by Suganthi et al. (2011) showed that the detrimental effect of aflatoxin on feed efficiency in birds 
appeared to be insignificant to the medium during the first 14 days of age and significant from days 15 to 42 . Grenier and Applegate (2013) reported that the apparent protein digestibility was decreased by 8 to $13 \%$ when the duck was subjected to very low concentrations of aflatoxin (20 and $40 \mathrm{ppb}$ ).

Continuous exposure to low doses of aflatoxin in humans and animals (rats, primate, and ducks) causes hepatocellular carcinoma, which is one of the most harmful type of cancer diseases (Benkerroum, 2020; Diaz \& Murcia, 2011). In a review by Wu \& Santella (2012), it is explained that in the body, AFB1 is metabolized by the cytochrome P-450 system at the 8,9 -vinyl bond to form AFB1-8,9- epoxide which is an unstable, reactive molecule. This molecule can bind covalently to DNA, producing AFB1-guanine adducts, and to protein, producing AFB1-albumin and other protein adducts. The configuration of AFB1-guanine adducts in hepatic DNA is critical for the carcinogenic effects of AFB1 in animals resulting in mutations in key genes.

The harmful effects of aflatoxin can be minimized by the addition of organic mycotoxin binders such as yeast, probiotics, antioxidant (Nalle et al., 2019; Fouad et al., 2019; Wade et al., 2017; Wade \& Sapcota, 2015; Girish \& Devegowda, 2006; Afzal \& Zahid, 2004), and inorganic mycotoxin binder, for example, sodium bentonite, clinoptilolite, and cyclopiazonic acid (Barati et al., 2017; Magnoli et al., 2011; Kumar \& Balachandran, 2009; Ortatatli et al., 2005). However, the efficacy of each type of mycotoxin binder depends on the aflatoxin level and species of birds. Fouad et al. (2019) reported that the addition of $0.5 \mathrm{~kg} /$ ton mycosorb did not improve the performance or immunity of birds fed aflatoxin diet (40 ppb AFB1/kg). Azeem et al. (2019) explain that Lactobacilli, a probiotic strain, have the capability to eliminate aflatoxin through binding the toxin to the cell wall rather than through metabolic degradation. Nazarizadeh \& Pourreza (2019) claimed that the inclusion of formycin, anzymit, and mycosorb in the complete feed having low level of AFB1 $(0,2$, and $4 \mu \mathrm{g} / \mathrm{g})$ resulted in the enhanced growth performance, hematology value, and serum protein on broiler chickens. According to Saki et al. (2018), mycosorb, a glucomannan-containing yeast product from cell wall, has the ability to absorb different mycotoxins by forming a stable complex to reduce the deleterious effect of mycotoxin in animals. Girish \& Devegowda (2006) explained that the mode of action of mycosorb in decreasing the relative organ weight was by binding the mycotoxin molecule in its glucomannan matrix, which hinder its absorption from gastrointestinal tract and the following toxin induction. According to Mogadam \& Azizpour (2011), feed aflatoxin diets (250 ppb) supplemented with glucomannan yeast and sodium bentonite ameliorates the performance and immunity of broiler chickens.

Considering the toxic effects of AFB1 in broilers and healthy food products, the issues for aflatoxin prevention and reduction are very crucial to be raised. In addition, the climate condition in Indonesia is certainly suitable for the growth of Aspergillus spp and their metabolites. Therefore, the strategy to prevent the growth of Aspergillus spp and their metabolites in feed ingredients or eliminate the harmful effects of aflatoxins in the diets should be extensively evaluated. Based on the aforementioned explanation, a study was designed to assess the response of birds subjected to a low level of aflatoxin B1 diets combined with an organic mycotoxin binder (mycosorb). Up to the present time, most studies use a pure AFB1 in the test diets to evaluate the efficacy of mycosorb to lower the toxic effect of AFB1 in birds. So, the results obtained from those studies may not be appropriate with the factual broiler farm condition. In the present study, the AFB1 used in the test diets was obtained from corn naturally contaminated with AFB1.

\section{MATERIALS AND METHODS}

\section{Animal Ethic Approval}

The Animal Ethic Committee of Faculty of Veterinary Medicine, University of Nusa Cendana Kupang-Indonesia approved the animal handling procedures of the current study, with Ethical Clearance Number KEH/FKH/NPEH/015/2019 on July $8^{\text {th }} 2019$.

\section{Birds and Housing}

The experiment was conducted in State Polytechnic of Agriculture Kupang, East Nusa Tenggara Province, Indonesia. A total of 240 one-day-old broilers (Cobbs strain) obtained from the local hatchery were used in the present trial. The birds, with the same initial body weights $(45.7 \pm 0.2 \mathrm{~g} / \mathrm{bird})$, were randomly distributed into 24 pens (10 birds/pen). The initial body weights of chicks were measured using a precision scale (max. 4000 g; readability $0.01 \mathrm{~g}$ ). From day 1 to day 21, the birds were kept on the floor pen with paddy husk litter. On day 22 , the birds were moved to 48 metabolic cages ( 5 birds each cage) in order to measure nutrient digestibility. During the first week, a gasolec was placed in the middle of the room to heat the chicks. Each pen was also added with a bulb (75 watts) for additional heating. During the trial period (35 days), the housing temperature and relative humidity were monitored by a thermohygrometer. The birds were provided with 20 hours of lighting every day. The bulb for lighting was placed on the ceiling.

\section{Ingredients}

Yellow corn (fresh and moldy), sago (putak meal), and commercial mycotoxin binder (Mycosorb, Alltech Ltd, Indonesia) were the major ingredients included in the present study. Mycosorb, a feed supplement anticaking agent, contains brewer's dried yeast, calcium carbonate, brewers fermentation soluble, and hydrated sodium calcium aluminosilicate. The crude protein and crude fiber contents of mycosorb are minimum $18 \%$ and maximum 4\%, respectively. Mycosorb product was obtained from Alltech Ltd distributor in Indonesia. The manufacture recommended dosage of Mycosorb is 0.500 to $2.000 \mathrm{~kg} /$ ton feed. In the present study, the dose of yeast glucomannan (mycosorb) included in the experimental diets was $0.750 \mathrm{~kg} / \mathrm{ton}$ feed. This myco- 
sorb dose was taken based on the concentration level naturally contaminated with aflatoxin was prepared by the following protocol: the fresh yellow corn with the initial moisture content of $14.5 \%$ was put in some plastic then wetted by the addition of clean water $(10 \%$ of corn weight) in order to speed the growth of Aspergillus flavus. The clean water addition was applied every other day for two months (modified method of Mogadam \& Azizpour, 2011). The moldy corn was sent to the laboratory (SEAMEO Biotrop Laboratory, Bogor, Indonesia) to analyze their aflatoxin level. The analysis of aflatoxin concentration of moldy corn was conducted three times during the two months of storage. The sampling proAFB1, AFB2, AFG1, and AFG2 was conducted with the the plastic sack and then ground with a hammer mill ( 3 mm screen size; KAL-EC.2, Electric Motor 3000 Rpm), mixed and sub-sampled according to sampling method developed by Campos \& Campos (1997). The reduced sample (1500 g) obtained from the previous method was then reduced by using a cone sample divider (RETSCH PT 100) to produce laboratory sample. The laboratory sample was reground using a sample mill (FOSS CT 193 Cyclotec $\left.^{\mathrm{TM}}\right)$ to produce an appropriate particle size $(0.5$ $\mathrm{mm}$ screen size) for aflatoxin analysis. The moldy corn, together with fresh corn samples, were packed and then sent to the laboratory for aflatoxin analysis. The AFB1 contents of moldy and fresh corns were tested with a Thin-Layer Chromatography (TLC) (SEAMEO Biotrop Laboratory, Bogor, Indonesia). The aflatoxin concentration of moldy corn was $134 \mathrm{ppb}$.

\section{Experimental Diets}

Two control diets (with and without mycosorb) composed of fresh corn, sago, soybean meal, meat and bone meal, and vegetable oil were formulated to meet the nutrient requirements of broilers (Table 1). The proportion of fresh corn in the control diets was replaced by moldy corn in the test diets. The proportion of moldy corn in the aflatoxin diets was determined using a dilution formula (Volume1 $\times$ Concentration1 = Volume $2 \times$ Concentration2) (Aly \& Anwer, 2009). The experimental diets were pelleted using a Pellet Mill with a capacity of 1.0 ton/hour and $4 \mathrm{~mm}$ pellet size, then crumbled using a crumbling machine (capacity: 100-200 kg/hour; roll tube diameter: 10 inch, screen size: $2 \mathrm{~mm}$ ). Pelleting Mill of State Polytechnic of Agriculture Kupang. The samples of treatment diets were then analyzed for their aflatoxin (B1, B2, G1, and G2) concentrations using HPLC (SEAMEO Biotrop Laboratory, Bogor, Indonesia). Treatment diets fed to the birds were in crumble (0 to $21 \mathrm{~d}$ ) and pellet (22 to $35 \mathrm{~d}$ ) forms. No antibiotics were given to the birds via either drinking water or feed throughout the trial. The drinking water was freely accessible during the experiment. of AFB1 implemented in the experimental diet. Corn sacks (50 kg capacity each). The fresh yellow corn was cedure of moldy corn to evaluate the concentrations of following protocol: the moldy corn was taken out from and crumbling processes were conducted in Mini Feed

\section{Experimental Design}

This 35-day trial composed of eight treatment combinations with three pen replications. The experiment was conducted in a completely randomized design with $4 \times 2$ factorial arrangement. The first factor was the level of aflatoxin B1 used consisted of 4 levels i.e., 0, 10.36, 26.97 , and $61.06 \mathrm{ppb}$. The second factos was mycosorb with 2 levels i.e., without $(0)$ and with mycosorb $(0.750$ $\mathrm{kg} /$ ton feed). The 8 combination of treatments were T1) the control diets (not detectable AFB1, nd) without mycosorb; T2) control diets (nd) + mycosorb; T3) AFB1 diets (10.36 ppb) without mycosorb; T4) AFB1 diets (10.36 $\mathrm{ppb})+$ mycosorb; T5) AFB1 diets (26.97 ppb) without mycosorb; T6) AFB1 diets (26.97 ppb) + mycosorb; T7) AFB1 diets (61.06 ppb) without mycosorb; and T8) AFB1 diets $(61.06 \mathrm{ppb})+$ mycosorb. The level of AFB1 applied in the treatment diets were based on the result of the previous studies (Fouad et al., 2019; Yang et al., 2012; Resamovic \& Sinovec, 2006) regarding the negative effects of AFB1 in the low concentration. Variables measured were feed intake (g/bird), body weight (BW) gain (g/bird), feed per gain $(\mathrm{g} / \mathrm{g})$, apparent nutrient digestibility coefficient, aflatoxin residues (ppb) in breast and liver, the relative length $(\mathrm{cm} / \mathrm{kg} \mathrm{BW})$ and weight $(\mathrm{g} / \mathrm{kg}$ $\mathrm{BW}$ ) of digestive organ, and histopathological changes of duodenum and jejunum of birds.

Table 1 . The composition ( $\mathrm{g} / 100 \mathrm{~g}$ as fed) of the control diets

\begin{tabular}{|c|c|c|}
\hline \multirow{2}{*}{$\begin{array}{l}\text { Feed ingredients } \\
\text { Maize }\end{array}$} & \multicolumn{2}{|c|}{ Inclusion level } \\
\hline & 51.19 & 51.19 \\
\hline Putak, CP 3.6\% & 3.98 & 3.98 \\
\hline Soybean meal, CP 44\% & 33.00 & 33.00 \\
\hline Meat and Bone Meal & 6.00 & 6.00 \\
\hline Vegetable oil & 4.00 & 4.00 \\
\hline DL-Methionine 99\% & 0.25 & 0.25 \\
\hline L-Lysine & 0.25 & 0.25 \\
\hline Limestone & 0.05 & 0.05 \\
\hline Dicalcium phosphate & 0.60 & 0.60 \\
\hline Salt & 0.25 & 0.25 \\
\hline Sodium bicarbonate & 0.12 & 0.12 \\
\hline Vitamin-Mineral Premix ${ }^{*}$ & 0.30 & 0.30 \\
\hline Mycosorb $^{* *}$ & - & 0.075 \\
\hline Total & 100.00 & 100.00 \\
\hline \multicolumn{3}{|l|}{ Nutrient composition (calculated) } \\
\hline $\begin{array}{l}\text { Apparent Metabolizable energy } \\
(\mathrm{kcal} / \mathrm{kg} \mathrm{DM})\end{array}$ & 3,100 & 3,100 \\
\hline Crude Protein (g/kg) & 210 & 210 \\
\hline Lysine $(\mathrm{g} / \mathrm{kg})$ & 12.7 & 12.7 \\
\hline Met + Cys (g/kg) & 9.7 & 9.7 \\
\hline AFB1 (ppb) & - & - \\
\hline \multicolumn{3}{|c|}{ 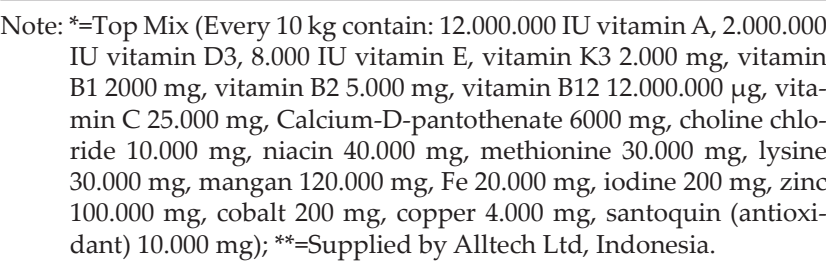 } \\
\hline
\end{tabular}




\section{Chemical Analysis}

The moisture content of fresh corn was determined using a convection oven $\left(105^{\circ} \mathrm{C}\right)$ based on AOAC method (2005). The aflatoxin (B1, B2, G1, and G2) concentrations of moldy corn were determined using a Thin-Layer Chromatography (TLC) with the standard procedure of AOAC Official Method 993.17 (Latimer, 2012).

The procedure of aflatoxin analysis using TLC was conducted through four major steps: extraction, the elimination of polar and non-polar impurities, identification, and quantification. The ground sample was extracted using methanol and then filtered. The sample filtrate was put into a flask and then added n-hexane to remove the fat and purified with chloroform. The chloroform fraction was collected and then evaporated to form a residue. The sample solution was streaked on a chromatographic plate using a micro syringe. A single standard aflatoxin solution or a mixture was also spotted on the same plate, depending on the type of aflatoxin to be identified. The chromatographic plate was inserted into the vessel containing the eluent and then eluted from the bottom up until the solvent reaches the limit. After drying using a dryer, it was observed under a UV lamp with a wavelength of $366 \mathrm{~nm}$. The qualitative test is carried out by comparing the mooring time of the sample and standard spots.

Meanwhile, the quantitative test was carried out by comparing the intensity of the sample and standard spots. Observation results were recorded on the Technical Form FT-PP-01-1. If aflatoxin B1 is detected (B2, G1, and G2 are not detected), the intensity of aflatoxin B1 and standard aflatoxin B1 emission will be observed. For this reason, a standard aflatoxin B1 series was prepared using a certain amount of standard $(1 ; 2$; 3; 4; 5; and $6 \mu \mathrm{L}$ ) whose concentrations were known. A similar procedure will also be conducted for aflatoxins B2, G1, and G2. If the sample spot luminescence intensity was higher than the most concentrated standard, dilution of the sample solution was then carried out for further recycling.

While the content of aflatoxin diets was analyzed using High Performance Liquid Chromatography (HPLC, limit of detection: $0.43 \mathrm{ppb}$ ) with the standard procedure of AOAC Official Method AOAC 49.2.18993.21 (Latimer, 2012). The principle of analysis using HPLC is as follows: the sample is extracted with methanol: water (70:30), then filtered, diluted, and passed through an immuno-affinity column which takes the specific monoclonal antibody of AFB1, AFB2, AFG1, and AFG2. The pure and isolated aflatoxin will be concentrated in the column and will be released from the antibody and methanol. The calculation of aflatoxin concentration was conducted using liquid chromatography with a fluorescence detector and post column derivatization. Aflatoxin post-column derivatization could increase the detection and or respond selectively to the HPLC detector.

\section{Determination of Nutrient Digestibility}

The apparent digestibility of nutrients was determined using total excreta collection (Nalle et al., 2010). The excreta from each cage were collected on days 32 to 35 and immediately stored in the freezer $\left(-20^{\circ} \mathrm{C}\right)$ to avoid the fermentation process. Then, the excreta of each cage (as an experimental unit) were defrosted, pooled, mixed, sub sampled, oven dried $\left(60^{\circ} \mathrm{C}\right)$, and ground using a 0.5 mm mesh screen on the CT 193 Cyclotec $^{\text {TM }}$ laboratory mill. The ground excreta and experimental diets were sent to the laboratory (Nutrition and Feed Laboratory, State Polytechnic of Agriculture Kupang, Indonesia) for further analysis of their dry matter contents (Memmert oven, $105^{\circ} \mathrm{C}$ ) and crude fat (Fat Extractor-Ankom XT10, fat ranges from $0 \%$ to $100 \%$ ).

\section{Aflatoxin Residue Determination}

On day 35, six birds from each treatment (2 birds/ pen) were selected and physically euthanized by cervical dislocation. Then the birds were dissected, and the liver of birds was removed. Afterward, the liver samples were oven dried $\left(60^{\circ} \mathrm{C}\right)$, and ground with a pestle and mortar, before being reground with a sample mill $(0.5$ $\mathrm{mm}$ screen size). The ground samples were packed and labeled and sent to the laboratory for aflatoxin analysis. The aflatoxin residues (AFB1, AFB2, AFG1, and AFG2) of liver samples were determined using LC-MS (Jettanajit and Nhujak, 2016; Garcia-Moraleja et al. 2015; PT Saraswanti Indo Genetech Laboratory, Bogor-Indonesia).

\section{Histopathological Changes Observation}

The histopathological changes observation was conducted in three stages which were: 1) sample preparation (Feed Technology Laboratory of State Polytechnic of Agriculture Kupang), 2) specimen preparation (Medical Faculty Laboratory of Nusa Cendana University), and 3) visual observation of duodenal and jejunal specimens (Animal Health Laboratory of State Polytechnic of Agriculture Kupang). The detailed procedure (Feng et al., 2017) was as follow: Forty-eight birds from each treatment were designated and humanely killed by atlanto-occipital joint dislocation. Then, the middle parts of the duodenal and jejunal samples (about $5 \mathrm{~cm}$ in length) were removed immediately. The samples were put into $10 \%$ formalin for 24 hours, and then assigned into $70 \%$ ethyl alcohol. Afterward, each duodenal or jejunal sample was trimmed, dehydrated, embedded into wax, blocked, segmented in $7 \mu$ m thickness, improved with hematoxylin-eosin, then mounted and observed using a digital microscope (Hirox KH-8700, Japan). The visual observation of the epithelial cell layer was made at 140x magnifications (mid-range resolution).

\section{Measurement}

Growth performance. The birds and feed were weighed using a digital scale on days 21 and 35 . The body weight gain was calculated by the difference between the final 
weight and the initial weight. The feed intake was obtained by the initial amount of feed given to the birds minus the left over. The mortality of birds as well as the weight of dead birds was documented daily, and these data were used to accurately determine the feed conversion ratio (FCR). The FCR was calculated using formula (Nalle et al., 2011):

$\mathrm{FCR}=$ feed intake / (weight gain + dead bird's weight)

Digestive tract size. The measurement of digestive tract size was conducted according to Nalle et al. (2011). On day 35, six birds from each treatment, with individual body weight closest to the mean weight of the pen, were selected, individually weighed and sacrificed by cervical dislocation. Then, before measuring the length $(\mathrm{cm})$, full, and empty weights $( \pm 0.1 \mathrm{~g})$ of each segment of gastrointestinal tract (from crop to colon) of birds, any adherent mesentery was removed. The body weight (BW) of each bird was used to calculate the relative length $(\mathrm{cm} / \mathrm{kg} \mathrm{BW})$ and weight of digestive organ $(\mathrm{g} / \mathrm{kg}$ BW).

Apparent nutrient digestibility coefficient was measured using the following formula (McDonald et al., 2003):

Digestible coefficient nutrient diet $=$

[(feed intake $\mathrm{x}$ nutrient diet) - (total excreta $\mathrm{x}$ nutrient excreta)] / (feed intake $x$ nutrient diet)

\section{Statistical Analysis}

The performance, selected internal organ size, and nutrient digestibility data acquired from the present study were subjected to statistical analysis according to the General Linear Model (GLM) procedure of SAS (University Edition, SAS Institute), using the two-way ANOVA. The treatments were considered to be significant at $\mathrm{p}<0.05$. Fisher's Least Significant Difference (LSD) test was used to calculate the significant differences between the means of treatment.

\section{RESULTS}

\section{Growth Performance}

The growth performance of broilers fed all treatment diets were represented in Table 2. AFB1 level $x$ mycosorb interaction was not significant in growth performance of broilers during the 21 days and 35 days of experiments. However, it seems that broilers fed AFB1 diet supplemented with mycosorb tended to have higher feed efficiency than those given aflatoxin diet without mycosorb.

Regarding the main effect of AFB1 level, except for FCR at the $35^{\text {th }}$ day of experiment, the level of AFB1 had no effect on all treatment parameters during the 35 days

Table 2. Feed intake (FI, g/bird), feed conversion ratio (FCR), and body weight gain (BWG, g/bird) of broilers fed diets containing low levels of aflatoxin B1 (AFB1) (ppb) and mycotoxin binder (Mycosorb)

\begin{tabular}{|c|c|c|c|c|c|c|c|}
\hline \multicolumn{2}{|c|}{ Treatments } & \multicolumn{6}{|c|}{ Variables } \\
\hline AFB1 level, ppb & Mycosorb & $\begin{array}{c}\text { FI } \\
(21 \mathrm{~d})\end{array}$ & $\begin{array}{c}\text { FI } \\
(35 \mathrm{~d})\end{array}$ & $\begin{array}{l}\text { FCR } \\
\text { (21d) }\end{array}$ & $\begin{array}{l}\text { FCR } \\
(35 d)\end{array}$ & $\begin{array}{l}\text { BWG } \\
\text { (21d) }\end{array}$ & $\begin{array}{l}\text { BWG } \\
\text { (35d) }\end{array}$ \\
\hline nd & - & 1067 & 2246 & 1.957 & 2.088 & 535 & 1084 \\
\hline nd & + & 1078 & 2115 & 1.874 & 1.883 & 575 & 1098 \\
\hline 10.36 & - & 1077 & 2169 & 2.052 & 2.194 & 522 & 1066 \\
\hline 10.36 & + & 1031 & 2352 & 1.773 & 1.782 & 587 & 1289 \\
\hline 26.97 & - & 1147 & 2387 & 1.885 & 1.916 & 587 & 1203 \\
\hline 26.97 & + & 974 & 2087 & 1.689 & 1.693 & 578 & 1198 \\
\hline 61.06 & - & 1135 & 2410 & 1.932 & 1.932 & 586 & 1254 \\
\hline 61.06 & + & 1260 & 2428 & 2.305 & 1.945 & 549 & 1202 \\
\hline SEM & & 116 & 181 & 0.206 & 0.142 & 31.5 & 71.18 \\
\hline \multicolumn{8}{|c|}{ Main effect, AFB1 Level (ppb, AL) } \\
\hline nd & & 1073 & 2181 & 1.915 & 1.986 & 555 & 1091 \\
\hline 10.36 & & 1053 & 2261 & 1.912 & 1.988 & 551 & 1142 \\
\hline 26.97 & & 1061 & 2237 & 1.787 & 1.805 & 583 & 1196 \\
\hline 61.06 & & 1198 & 2419 & 2.112 & 1.939 & 568 & 1228 \\
\hline SEM & & 82.0 & 128 & 0.146 & 0.101 & 22.2 & 50.30 \\
\hline \multicolumn{8}{|l|}{ Main effect, Mycosorb (M) } \\
\hline- & & 1107 & 2303 & 1.956 & $2.033^{\mathrm{a}}$ & 558 & 1151 \\
\hline+ & & 1086 & 2246 & 1.910 & $1.826^{\mathrm{b}}$ & 571 & 1196 \\
\hline SEM & & 58.0 & 91 & 0.103 & 0.071 & 15.7 & 35.4 \\
\hline \multicolumn{8}{|l|}{$\operatorname{Pr}>\mathrm{F}$} \\
\hline AFB1 Level (AL) & & NS & NS & NS & NS & NS & NS \\
\hline Mycosorb (M) & & NS & NS & NS & $*$ & NS & NS \\
\hline $\mathrm{AL} \times \mathrm{M}$ & & NS & NS & NS & NS & NS & NS \\
\hline
\end{tabular}

Note: Means in the same column with different superscripts differ significantly $(\mathrm{p}<0.05)$; ${ }^{*}=$ Significant $(\mathrm{p}<0.05)$; NS= Not Significant; nd $=$ non detectable level (Limit of detection with HPLC: AFB1 $=0.43 \mathrm{ppb})$. Each value was the average of three replicates (10 birds/replicate). 
trial period. The birds receiving mycosorb diets had better FCR $(p<0.05)$ than those fed control diets at the end of trial period (d35). The average FCR of growing birds fed diet with mycosorb was found to be significantly lower $(1.826)(p<0.05)$ than those given diets without mycosorb (2.033).

\section{Nutrient Digestibility}

Table 3 represents the apparent nutrient digestibility coefficient values. AFB1 level x mycosorb supplementation did not significantly affect the apparent digestibility coefficient of dry matter (ADCDM).

The level of AFB1 alone did not affect the ADCDM, but it significantly affected $(\mathrm{p}<0.05)$ the apparent digestibility coefficient of crude fat (ADCCF). The ADCCF of birds given the highest AFB1 diet (61.06 ppb) decreased significantly $(p<0.05)$. However, the ADCCF of birds receiving $10.36 \mathrm{ppb}$ and $26.97 \mathrm{ppb}$ AFB1 in the diets were observed to be comparable ( $p>0.05)$ to that of control.

\section{Digestive Tract Size}

The macroscopic change of the gastrointestinal tract of the birds was depicted in Table 4. AFB1 level $x$

Table 3. Apparent digestibility coefficients of dry matter and crude protein of broilers fed diets containing low level of aflatoxin B1 (AFB1) and mycotoxin binder (Mycosorb)

\begin{tabular}{|c|c|c|c|}
\hline \multicolumn{2}{|l|}{ Treatments } & \multicolumn{2}{|c|}{ Digestibility coefficient } \\
\hline AFB1 Level, ppb & Mycosorb & Dry matter & Crude fat \\
\hline nd & - & 0.781 & 0.761 \\
\hline nd & + & 0.809 & 0.775 \\
\hline 10.36 & - & 0.794 & 0.729 \\
\hline 10.36 & + & 0.782 & 0.723 \\
\hline 26.97 & - & 0.774 & 0.745 \\
\hline 26.97 & + & 0.818 & 0.696 \\
\hline 61.06 & - & 0.815 & 0.571 \\
\hline 61.06 & + & 0.769 & 0.706 \\
\hline SEM & & 0.018 & 0.037 \\
\hline \multicolumn{4}{|c|}{ Main effect, AFB1 Level (ppb, AL) } \\
\hline nd & & 0.795 & $0.768^{\mathrm{a}}$ \\
\hline 10.36 & & 0.788 & $0.726^{\mathrm{a}}$ \\
\hline 26.97 & & 0.796 & $0.721^{\mathrm{a}}$ \\
\hline 61.06 & & 0.792 & $0.638^{\mathrm{b}}$ \\
\hline SEM & & 0.013 & 0.026 \\
\hline \multicolumn{4}{|c|}{ Main effect, Mycosorb (M) } \\
\hline- & & 0.791 & 0.702 \\
\hline+ & & 0.794 & 0.725 \\
\hline SEM & & 0.009 & 0.018 \\
\hline \multicolumn{4}{|l|}{$\operatorname{Pr}>\mathrm{F}$} \\
\hline AFB1 Level (AL) & & NS & NS \\
\hline Mycosorb (M) & & NS & NS \\
\hline $\mathrm{AL} \times \mathrm{M}$ & & NS & * \\
\hline
\end{tabular}

Note: Means in the same column with different superscripts differ significantly $(\mathrm{p}<0.05) ; *=$ Significant $(\mathrm{p}<0.05) ; \mathrm{NS}=$ Not Significant; nd= non-detectable level (Limit of detection with HPLC: AFB1= $0.43 \mathrm{ppb}$ ). Each value was the average of three replicates (5 birds/ replicate). mycosorb interaction did not significantly affect the size of digestive organ of the birds. The main effect of AFB1 level and mycosorb supplementation did not influence the relative weight of almost all digestive organs. The weight of proventriculus relative to body weight of the birds fed the control diets (nd) was higher $(\mathrm{p}<0.05)$ than those receiving AFB1 diets (10.36 to $61.06 \mathrm{ppb}$ ). No interaction was found between the AFB1 level and mycosorb on the digestive organ length and weight of growing broilers. The main effect of AFB1 was observed to be significant $(p<0.01)$ for the relative weight of liver. Birds fed the highest amount of AFB1 in the diets (61.06 ppb) had higher $(p<0.05)$ relative weight of liver than those fed a control diet and low amount of AFB1 (10.26 and 26.97 ppb AFB1).

\section{Histopathological Changes and Aflatoxin Residues}

The liver color was normal in the control diet, 10.36 ppb, and 26.97 ppb AFB1 diets (Figure 1). The abnormality of liver color (darker color) was only observed in the treatment diet containing 61.06 ppb AFB1 (without mycosorb). A pale white color of the liver was observed in the $61.06 \mathrm{ppb}$ AFB1 diets added with mycosorb (0.75 $\mathrm{g} / \mathrm{kg})$.

The histological changes of duodenum and jejunum of birds fed treatment diets are depicted in Figure 2. Duodenum and jejunum sections of the birds fed control diets with and without mycosorb did not show a ruptured blood vessel. The ruptured blood vessel in duodenum and jejunum sections of the birds was observed in the majority of aflatoxin contaminated diets (10.36 to 61.06 ppb AFB1) with or without mycosorb.

The AFB1 residue in the liver and breast meat of birds are shown in Table 5 . The present results proved that the AFB1 residue was undetected in the liver and breast meat of broilers fed all treatment diets.

\section{DISCUSSION}

\section{Growth Performance}

Published data have shown that the toxicity of aflatoxin negatively affect the productivity, reproductive performance, morphological and histopathological changes, as well as immune system of birds (Saleemi et al., 2020; Mogadam \& Azizpour, 2011; Magnoli et al., 2011; Bryden, 2012; Yunus et al., 2011; Peng et al., 2015). According to Fouad et al. (2019), the concentration of aflatoxin in feed was the main factor associated with the occurrence of aflatoxicosis in poultry. The author also explained that deleterious impacts of aflatoxin in productivity and reproductive performance could occur even at the low concentration of aflatoxin. Therefore, it is crucial to do a comprehensive study, such as in the present experiment, to find out the best method to prevent and cure the aflatoxicosis in birds.

In the present study, the strategy that had been implemented to ameliorate the adverse effect of aflatoxin was by using the mycotoxin binder. A commercial mycotoxin binder product (yeast glucomannan or mycosorb) was applied to diets containing naturally 
Table 4. The digestive tract development of broilers fed diets containing low levels of AFB1 and Mycosorb

\begin{tabular}{|c|c|c|c|c|c|c|c|c|c|c|c|c|c|c|c|}
\hline \multicolumn{2}{|l|}{ Treatments } & \multicolumn{3}{|c|}{$\begin{array}{c}\text { Relative organ weight } \\
\text { (g/kg BW) }\end{array}$} & \multicolumn{6}{|c|}{$\begin{array}{c}\text { Relative empty weight } \\
(\mathrm{g} / \mathrm{kg} \mathrm{BW})\end{array}$} & \multicolumn{5}{|c|}{$\begin{array}{l}\text { Relative length } \\
(\mathrm{cm} / \mathrm{kg} \mathrm{BW})\end{array}$} \\
\hline $\begin{array}{l}\text { AFB1 } \\
\text { Level } \\
(\mathrm{ppb})\end{array}$ & $\begin{array}{l}\text { Myco- } \\
\text { sorb }\end{array}$ & Liver & Spleen & $\begin{array}{l}\text { Pan- } \\
\text { creas }\end{array}$ & Crop & $\begin{array}{l}\text { Proven- } \\
\text { triculus }\end{array}$ & Gizzard & $\begin{array}{l}\text { Duode- } \\
\text { num }\end{array}$ & $\begin{array}{l}\text { Jeju- } \\
\text { num }\end{array}$ & Ileum & $\begin{array}{l}\text { Proven- } \\
\text { triclulus }\end{array}$ & Gizzard & $\begin{array}{l}\text { Duode- } \\
\text { num }\end{array}$ & $\begin{array}{l}\text { Jeju- } \\
\text { num }\end{array}$ & Ileum \\
\hline nd & - & 28.4 & 1.35 & 2.24 & 3.72 & 8.01 & 22.9 & 11.1 & 14.2 & 8.79 & 4.82 & 5.91 & 39.6 & 88.4 & 62.8 \\
\hline nd & + & 25.4 & 1.38 & 2.39 & 3.18 & 6.31 & 15.6 & 8.41 & 11.1 & 7.60 & 3.03 & 3.77 & 29.6 & 61.6 & 47.3 \\
\hline 10.36 & - & 28.9 & 1.38 & 2.83 & 3.13 & 5.06 & 20.0 & 8.01 & 11.9 & 10.6 & 3.33 & 4.72 & 31.2 & 68.7 & 62.9 \\
\hline 10.36 & + & 25.8 & 1.38 & 2.51 & 2.76 & 5.01 & 18.9 & 7.84 & 13.8 & 7.41 & 2.89 & 3.97 & 27.8 & 61.6 & 44.7 \\
\hline 26.97 & - & 29.7 & 1.27 & 2.29 & 2.44 & 4.78 & 16.2 & 6.68 & 13.3 & 7.63 & 3.42 & 4.62 & 29.3 & 69.9 & 53.1 \\
\hline 26.97 & + & 26.2 & 1.19 & 2.26 & 3.72 & 5.03 & 20.5 & 7.54 & 12.9 & 7.66 & 3.49 & 4.59 & 30.5 & 64.5 & 48.2 \\
\hline 61.06 & - & 35.9 & 1.36 & 1.89 & 2.40 & 5.21 & 21.7 & 8.87 & 13.1 & 7.93 & 3.12 & 4.60 & 29.7 & 64.7 & 46.7 \\
\hline 61.06 & + & 35.5 & 1.51 & 2.78 & 2.95 & 6.03 & 19.8 & 9.02 & 16.2 & 9.85 & 4.02 & 5.16 & 38.6 & 84.8 & 63.0 \\
\hline SEM & & 2.084 & 0.246 & 0.353 & 0.437 & 0.505 & 1.65 & 1.15 & 2.17 & 1.41 & 0.463 & 0.563 & 4.443 & 11.11 & 8.65 \\
\hline \multicolumn{16}{|c|}{ Main factor, AFB1 Level (ppb, AL) } \\
\hline nd & & $26.9^{b}$ & 1.37 & 2.32 & 3.45 & $7.16^{\mathrm{a}}$ & 19.2 & 9.77 & 12.7 & 8.19 & 3.93 & 4.84 & 34.6 & 74.9 & 55.1 \\
\hline 10.36 & & $27.4^{\mathrm{b}}$ & 1.38 & 2.67 & 2.94 & $5.03^{\mathrm{b}}$ & 19.5 & 7.93 & 12.9 & 8.85 & 3.11 & 4.35 & 29.5 & 65.1 & 53.8 \\
\hline 26.97 & & $27.9^{\mathrm{b}}$ & 1.16 & 2.28 & 3.10 & $4.90^{\mathrm{b}}$ & 18.4 & 7.11 & 13.1 & 7.65 & 3.46 & 4.60 & 29.9 & 67.2 & 50.7 \\
\hline 61.06 & & $35.7^{\mathrm{a}}$ & 1.44 & 2.32 & 2.68 & $5.62^{\mathrm{b}}$ & 20.7 & 8.95 & 14.6 & 8.89 & 3.57 & 4.88 & 34.1 & 74.7 & 54.9 \\
\hline SEM & & 2.084 & 0.174 & 0.249 & 0.309 & 0.357 & 1.17 & 0.811 & 1.54 & 0.995 & 0.327 & 0.398 & 3.141 & 8.78 & 6.12 \\
\hline \multicolumn{16}{|c|}{ Main factor, Mycosorb (M) } \\
\hline- & & 30.7 & 1.31 & 2.31 & 2.93 & 5.76 & 20.2 & 8.67 & 13.1 & 8.74 & 3.67 & 4.97 & 32.4 & 72.9 & 56.4 \\
\hline+ & & 28.3 & 1.36 & 2.48 & 3.15 & 5.59 & 18.7 & 8.20 & 13.5 & 8.05 & 3.36 & 4.34 & 31.6 & 68.1 & 50.8 \\
\hline SEM & & 1.042 & 0.123 & 0.176 & 0.219 & 0.257 & 0.825 & 0.573 & 1.09 & 0.703 & 0.231 & 0.281 & 2.22 & 5.56 & 4.32 \\
\hline \multicolumn{16}{|l|}{$\operatorname{Pr}>F$} \\
\hline $\begin{array}{l}\text { AFB1 } \\
\text { Level (AL) }\end{array}$ & & $* *$ & NS & NS & NS & ** & NS & NS & NS & NS & NS & NS & NS & NS & NS \\
\hline $\begin{array}{l}\text { Mycotoxin } \\
\text { binder }(\mathrm{M})\end{array}$ & & NS & NS & NS & NS & NS & NS & NS & NS & NS & NS & NS & NS & NS & NS \\
\hline $\mathrm{AL} \times \mathrm{M}$ & & NS & NS & NS & NS & NS & NS & NS & NS & NS & NS & NS & NS & NS & NS \\
\hline
\end{tabular}

Note: Means in the same column with different superscripts differ significantly $(\mathrm{p}<0.05)$; ${ }^{* *}=$ Significant $(\mathrm{p}<0.01)$; NS= Not significant; $\mathrm{nd}=$ non-detectable level (Limit of detection with HPLC: AFB1 $=0.43 \mathrm{ppb}$. Each value was the average of two replicates ( 2 birds/replicate).

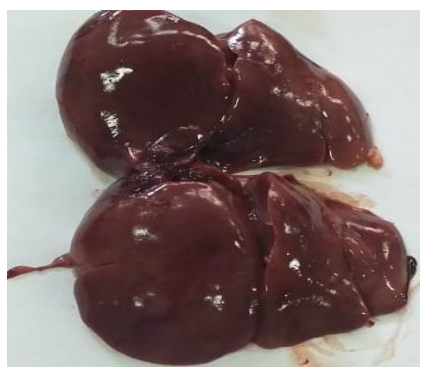

$61.06 \mathrm{ppb}$ AFB1

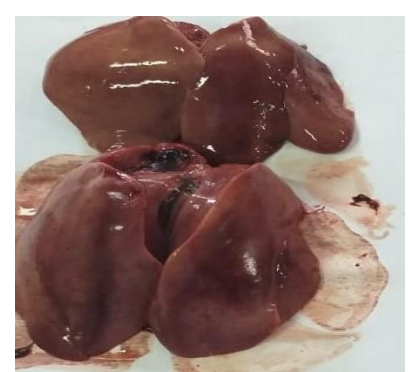

$61.06 \mathrm{ppb}$ AFB1 + mycosorb
Figure 1. Representative liver color of broilers (35 d) fed diets containing $61.06 \mathrm{ppb}$ aflatoxin B1 (AFB1) added with mycotoxin binder (Mycosorb)

contaminated AFB1 in four different levels, i.e., not detectable (nd), $10.36 \mathrm{ppb}, 26.97 \mathrm{ppb}$, and $61.06 \mathrm{ppb}$. In general, the supplementation of mycosorb in AFB1 diets did not ameliorate the performance of birds during the 35 days experiment. This result indicated that the inefficacy of mycosorb on this parameter was probably due to the birds did not show any negative effects as a result of AFB1 addition to their diet. The result agreed with Fouad et al. (2019), who reported that the addition of mycosorb at the level of $0.5 \mathrm{~kg} /$ ton did not improve the performance or immunity in birds fed 40 ppb AFB1 diet. The efficacy of mycosorb in ameliorating the per- formance of broilers was only observed in the diets containing a high concentration $(0,2$, and 4 ppm) of AFB1 (Nazarizadeh \& Pourreza, 2019).

As was shown in Table 2, the level of AFB1 $(\leq 61.06$ $\mathrm{ppb}$ ) had no effect on the growth performance of birds during the experiment (21d and 35d). However, it seems that the average feed per body weight gain of starting broilers (21d), that received diets containing the highest level of AFB1 (61.06 ppb), was slightly higher than those fed lower levels of AFB1 diets ( $\leq 26.97 \mathrm{ppb})$. This result was partly corresponding to those published by Yang et al. (2012), who showed that the performance of young birds (1-21d) was not affected by feeding diets containing low level of AFB1 (16.3 ppb) but, when the level of AFB1 increased to 36.9 and $82.4 \mathrm{ppb}$, the performance of birds was reduced significantly. Furthermore, the authors also noticed that the group of birds given 34.3 and $69.3 \mathrm{ppb}$ of AFB1 had comparable performance, but it was depressing when the level of AFB1 in the diets increased to 95.2 and $134 \mathrm{ppb}$. Previous studies (Liu et al. 2018; Resanovic \& Sinovec, 2006) claimed that the productivity of birds fed aflatoxin-treated diets (40 to $44.5 \mathrm{ppb}$ ) was inferior than those fed control diets. This discrepancy was probably due to the difference in methodology. In the present study, the aflatoxin corn used was naturally contaminated by Aspergillus spp. while, in the study by Liu et al. (2018), the type of aflatoxin used was pure aflatoxin. 


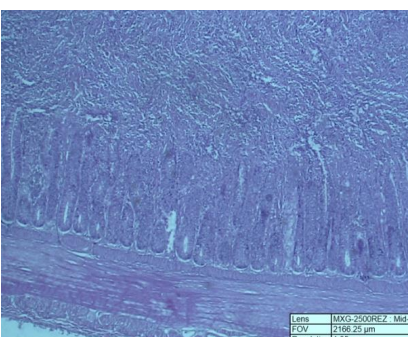

Duodenum (nd)

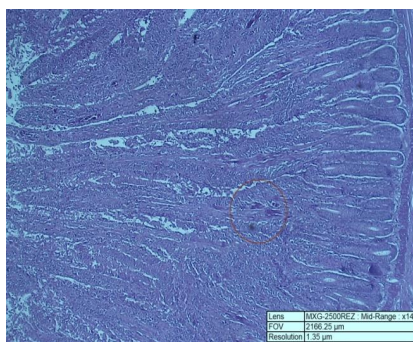

Duodenum (26.97 ppb AFB1)

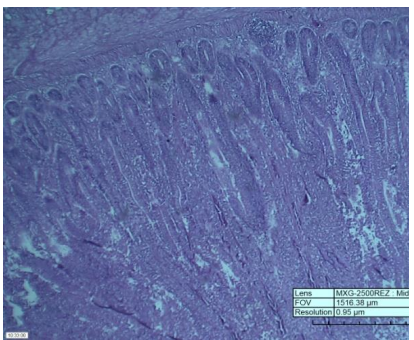

Jejunum (nd, control)

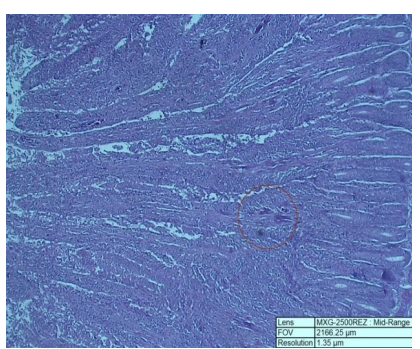

Jejunum (26.97 ppb AFB1)

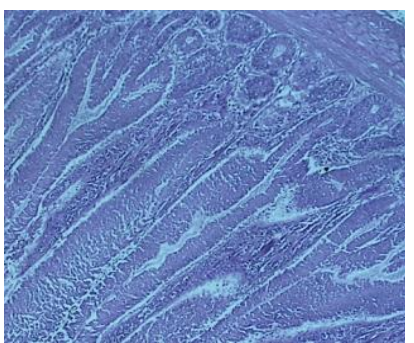

Duodenum (nd + Mycosorb)

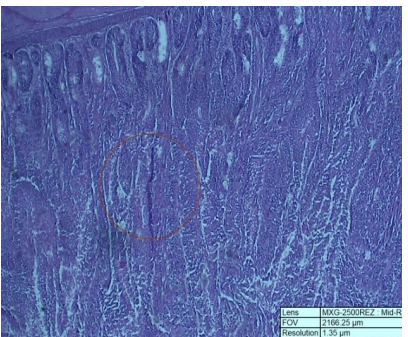

Duodenum (26.97 ppb AFB1+ mycosorb)

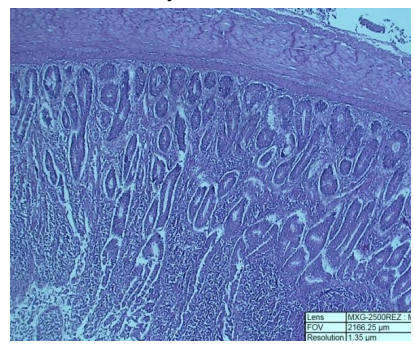

Jejunum (nd + mycosorb)

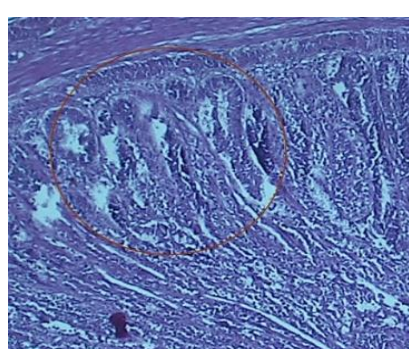

Jejunum (26.97 ppb AFB1+ mycosorb)

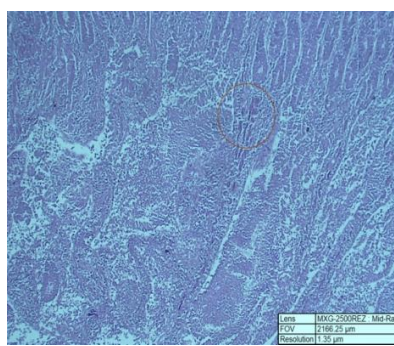

Duodenum (10.36 ppb AFB1)

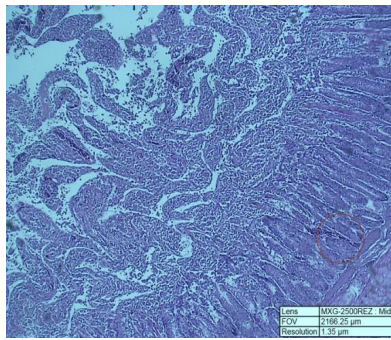

Duodenum (61.06 ppb AFB1)

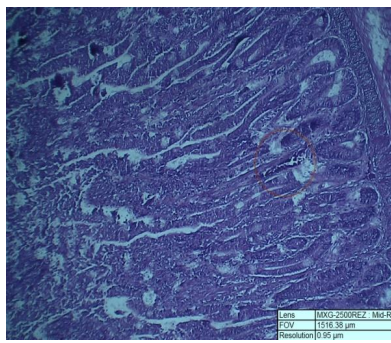

Jejunum (10.36 ppb AFB1)

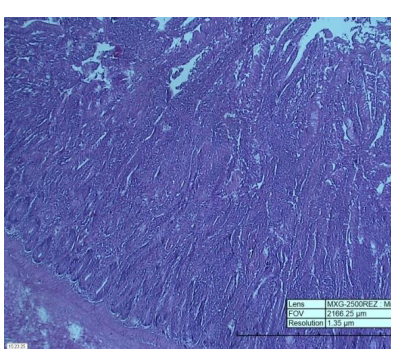

Jejunum (61.06 ppb AFB1)

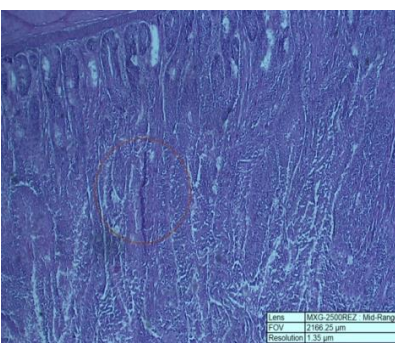

Duodenum (10.36 ppb AFB1+ mycosorb)

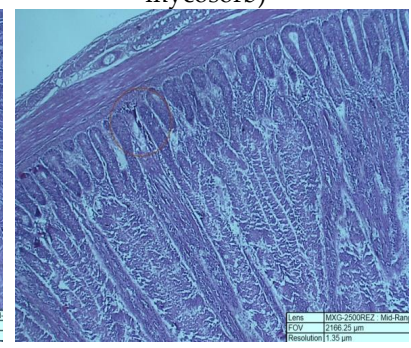

Duodenum (61.06 ppb AFB1+ mycosorb)

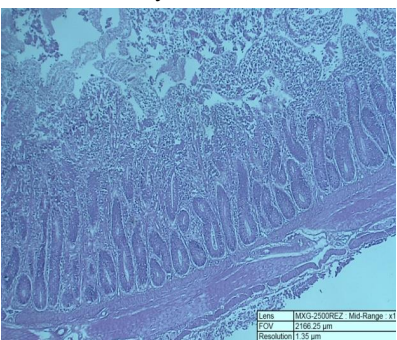

Jejunum (10.36 ppb AFB1 + mycosorb)

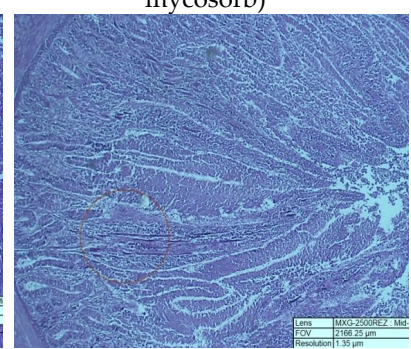

Jejunum (61.06 ppb AFB1+ mycosorb)

Figure 2. Photomicrographs of duodenum and jejunum sections of broilers ( $35 \mathrm{~d}$ ) fed all treatment diets

Table 5. Aflatoxin B1 residues in liver and breast meat of broilers fed dietary Mycosorb*

\begin{tabular}{cccccc}
\hline \multicolumn{2}{c}{ Treatments } & & \multicolumn{2}{c}{ AFB1 Residue (ppb) } \\
\cline { 1 - 2 } \cline { 5 - 6 } AFB1 level $(\mathrm{ppb})$ & Mycosorb & & Liver & Breast Meat \\
\hline nd & - & & nd & nd \\
nd & + & & nd & nd \\
10.36 & - & & nd & nd \\
10.36 & + & & nd & nd \\
26.97 & - & & nd & nd \\
26.97 & + & & nd & nd \\
61.06 & - & & nd & nd \\
61.06 & + & & nd & nd \\
\hline
\end{tabular}

Note: $\mathrm{nd}=$ non detectable level (Limit of detection with LC-MS: AFB1= $0.02 \mathrm{ppb}){ }^{*}=$ Each value was the average of two replicates ( 2 birds/ replicate).
During the 35 days of experiment, the inclusion of mycosorb $(0.750 \mathrm{~g} / \mathrm{kg})$ in the diets ameliorated the feed conversion ratio (FCR) of birds, which agreed with Mogadam \& Azizpour (2011). As were shown in Table 2, birds fed diets containing $0.750 \mathrm{~g} / \mathrm{kg}$ mycosorb had better FCR (1.826) compared to those fed diets without mycosorb (2.033). The improvement of FCR on day 35 was probably due to the efficacy of yeast glucomannan to bind AFB1 in the intestine of birds during the starter period, so the nutrient digestibility and availability of diets might increase.

It is interesting to note that the FCR of birds fed control diets added with mycosorb was better than those fed control diets without mycosorb (Table 2). The improvement in FCR of birds fed control diets added with mycosorb was probably due to the ability of mycosorb to absorb other mycotoxins, which might be present in 
the control diets which are not analyzed. The yellow corn used did not contain AFB1, but other feed ingredients may contain other mycotoxins which were not analyzed.

The inefficacy of mycosorb in supporting the growth performance of growing broilers observed in the present experiment was supported by previous study (Fouad et al., 2019). On the other hand, Nazarizadeh \& Pourezza (2019) claimed that the addition of mycosorb A+ into an aflatoxin contaminated diet increased the feed efficiency of birds. The differences were probably due to the concentrations of mycosorb and aflatoxin used in the diets.

\section{Nutrient Digestibility}

It is generally accepted that aflatoxin B1 (AFB1) plays an important role in gut damage, macronutrient malabsorption syndrome, and digestive enzyme activities (Han et al., 2008; Yunus et al., 2011; Grenier \& Applegate, 2013; Feng et al., 2017). The digestive enzymes are essential for starch, fat, and protein digestions. The disturbance of digestive enzyme production and activity will lead to changes in intestinal villi morphology and lower nutrient digestibility (Grenier \& Applegate, 2013). In addition, the chronic exposure of AFB1 causes lesions in the gastrointestinal tract parts (i.e. gizzard and small intestine) which may lead to a decrease in nutrient digestion and absorption. The increase in undigested nutrients in the bird's gut will in turn increase the population of pathogenic microbial which used these undigested nutrients for reproduction. Therefore, the supplementation of mycosorb or other toxin binders is crucial to ameliorate the nutrient digestibility of birds chronically exposed to AFB1. The supplementation of mycosorb is expected to absorb aflatoxin and form a stable complex to decrease the toxic effect of aflatoxin (Saki et al., 2018).

It is revealed from the present work that the inclusion of Mycosorb in the low level AFB1 diets $(\leq 61.06$ $\mathrm{ppb}$ ) had no valuable influence on dry matter and crude fat digestibility (Table 3), which was in agreement with Saki et al. (2018).

In the current study, the apparent digestibility coefficient of dry matter (ADCDM) remains unaffected when the toxic levels of AFB1 are relatively low ( $\leq$ $61.06 \mathrm{ppb}$ ), at least for a 35 days experimental period, which was similar to the results reported by Yang et al. (2012). Saki et al. (2018) even proved that the apparent dry matter digestibility had not been influenced by including higher level of AFB1 in the dietary treatments ( $1 \mathrm{mg} / \mathrm{kg}$ AFB1). The ADCDM in all dietary treatments ranged from 0.788 to 0.796 , which were slightly higher than those discovered by Yang et al. (2012) and Saki et al. (2018).

Even though the production and digestive enzyme activity were not measured in the present study, the finding of the present study indicated that the AFB1 might not negatively affect the production and activity of most digestive enzymes in the pancreas and small intestine of birds during this period of time (35d).
Consequently, the digestion and absorption processes might not be disturbed and still occur normally. The normal digestion process was supported by the histopathological observation (Fig 2), showing that the ruptured blood vessel of birds fed AFB1 diets was only observed in one to two spots along the villi of duodenum and jejunum of birds. The unchanged weight of pancreas of birds fed aflatoxin-treated diets also indicates the production and activity of most digestive enzymes in pancreas are not disturbed. In a review by Grenier \& Applegate (2013), it was explained that aflatoxin could modulate the productivity and activity of enzymes and transporters which lead to the abnormality of gut morphology and lowered nutrient digestibility and absorption. The toxic effect of aflatoxin on the production and activity of digestive enzymes was depended on the aflatoxin concentration, the duration of exposure to alflatoxin, and bird's species (Grenier \& Applegate, 2013).

The toxic effect of AFB1 on nutrient digestibility was only observed in apparent digestibility coefficient of crude fat (ADCCF), especially in the group of birds fed the highest concentration of AFB1 (61.06 ppb), but not in the diets with lower level of AFB1 (10.36 and $26.97 \mathrm{ppb})$. This result was probably due to the enlarged liver found in birds fed the highest AFB1 diets. The enlarged liver was associated with liver malfunctions (Fouad et al., 2019). The ADCCF was significantly lower by $16.9 \%$ in $61.06 \mathrm{ppb}$ AFB1-treated group compared to the control group. The ADCCF of 10.36 and 26.97 ppb AFB1-treated diets remained unchanged after 35 days of chronic exposure to toxin. The results in the present work partly agreed with the results reported by Han et al. (2008) in duck, particularly in feeding $\leq 40 \mathrm{ppb}$ AFB1 diet. The perceived differences in ADCCF as a consequence of prolonged aflatoxicosis might be attributable to the disparities in methodology and AFB1 response of each individual of birds.

The reason for the decreased apparent crude fat digestibility recorded in the diets with the highest AFB1 level (61.06 ppb) was not clear since the relative weight of pancreas of birds fed diets with the highest AFB1 concentration did not change (Table 4). As it is well known that lipase is produced in pancreas, so the unchanged relative weight of pancreas might indicate that the production and activity of lipase were still stable and would not reduce the fat digestibility. However, a study conducted by Han et al. (2008) proved that the enlarged pancreas of birds fed afla-treated diets (up to $40 \mathrm{ppb}$ ) did not change the digestibility of fat. The authors also did not measure the lipase activity in the small intestine of ducks fed afla-treated diets, so it could not be explained why the fat digestibility was still unchanged. On the other hand, a study conducted by Matur et al. (2010) showed that feeding low level of AFB1 diets (0 and $100 \mathrm{ppb}$ ) did not increase the weight of pancreas but decreased the activity of lipase in pancreas and duodenum of breeder hen. Based on the finding of Matur et al. (2010), the decreased crude fat digestibility in group of birds fed the highest AFB1 level (61.06) was probably due to the decreased lipase activity in duodenum and jejunum of birds. In this study, however, the lipase ac- 
tivity in the pancreas and the segment parts of intestine was not measured, so the indicator for low lipase activity cannot be showed.

The absorption of fat in the present study could be affected since it was found that there were a few ruptured blood vessels in the villi of duodenum and jejunum of birds fed AFB1-treated diets (Fig 2). According to Abbasi et al. (2018), AFB1 will be bio-transformed into AFBO (AFB1 epoxide) which will inhibit the digestion and nutrient absorption in the small intestine.

Regarding the second main factor, mycosorb, the inclusion of this factor had no effect on the apparent dry matter digestibility coefficient. The comparison is difficult to be made because the published data regarding the efficacy of mycosorb on the diets containing low level of AFB1 are scant. Saki et al. (2018) recorded from their study that the dry matter digestibility remained unchanged after feeding broilers with diets containing 1 ppm AFB1 added with 0.25\% mycosorb.

\section{The Size of Digestive Tract}

In this study, the relative weight of proventriculus of birds fed all levels of AFB1-treated diets was lower than those birds fed control diets. The decreased relative weight of proventriculus was possibly related to the reduced activity in the proventriculus of birds fed AFB1 diets. The result of the present study did not agree with the previous studies (Fani Makki et al., 2016; Feng et al., 2017). These discrepancies were probably due to a number of factors such as exposure dosage, type of birds, and individual bird's response. According to Kumar \& Balachandran (2014), the proventriculus of birds fed aflatoxin diets showed infiltration of mononuclear cells in the mucosa of proventriculus and crypt elongation during the starting period ( 0 to $21 \mathrm{~d}$ ). On day 42 , the lamina propria showed edema and mononuclear cell infiltration.

The enlarged liver discovered in birds fed diets containing $61.06 \mathrm{ppb}$ AFB1 was in accordance with the results reported by Han et al. (2008). According to Fouad et al. (2019), AFB1 causes liver malfunctions which could lead to the swollen liver. In addition, the authors explained that the enlarged liver might generate imbalanced lipid metabolism, trigger lipid deposition, inhibit antioxidant enzymes activity, augment lipid peroxidation and pro-inflammatory cytokines, and enhance hepatocyte apoptosis.

Feeding diets containing low level of aflatoxin (10.36 to $61.06 \mathrm{ppb}$ ) did not increase the relative weight of pancreases of the experimental birds. The published data regarding the effect of low level of AFB1 on pancreatic weight are scarce, so comparisons are difficult to make. Han et al. (2008) showed that the pancreas sizes of ducks given diets containing 20 and 40 ppb aflatoxin were bigger than those fed a control diet. Therefore, this result suggests that the aflatoxicosis is more severe in the ducks than in the broilers. The increased relative weight of pancreases of ducks was probably as a result of the increased mature crystalline granules in the cells of pancreas (Fouad et al., 2019).
It is generally accepted that mycotoxin is processed and detoxified in the liver organ so the body is protected from the toxic effect of mycotoxin (Fouad et al., 2019). Consequently, the morphological change of liver will lead to the change in the metabolism of lipid, protein, and amino acids in the liver. The present study revealed that the relative weight of liver in the experimental bird did not enlarge after chronic exposure to low AFB1 diets $(\leq 61.06 \mathrm{ppb})$. The result was in agreement with the report of Ortatatli et al. (2005), who found that the liver weight of birds fed 50 and even $100 \mu \mathrm{g} / \mathrm{kg}$ of dietary AFB1 were similar to those fed control diets. According to Magnoli et al. (2011), hepatic lesion reduced productivity, and lowered body immunity system are the common symptoms of aflatoxicosis.

\section{Histopathological Changes and Aflatoxin Residues}

The texture of liver from all of the experimental birds treated with aflatoxin diets remains unchanged (stay soft), and the change was only observed in color. As was shown in Figure 1, the beneficial effect of mycosorb in aflatoxin contaminated diets was the change in the liver color to pale white; while the liver color of birds fed aflatoxin contaminated diets without mycosorb was a slightly darker color. A previous study conducted by Magnoli et al. (2011) showed that the addition of a different toxin binder (sodium bentonite) changed the liver color to pale yellow.

Published data have shown that long term exposure to aflatoxin in the human body causes a number of chronic and acute diseases, including carcinogenic disease (i.e., liver cancer) and hepatitis B virus infection (Benkerroum, 2020; Rushing \& Selim, 2018; Chu et al., 2017; Carvajal-Moreno, 2015). A study conducted by Goodarzi et al. (2018) showed that $4.7 \%$ of all cancers in the world were associated to hepatocellular carcinoma (liver cancer), with Asian continent being the highest incident of this disease $(72.5 \%)$. The highest mortality rate caused by liver cancer was also found in Asian continent 72.4\% (Goodarzi et al., 2018). According to The American Cancer Society (2019), the most general signs of hepatocellular carcinoma (liver cancer) are 1) weight loss, 2) loss of appetite, 3) feeling very full after a small meal, 4) nausea or vomiting, 5) enlarged liver and spleen, 6) pain in abdomen, 7) swelling or fluid buildup in the abdomen (belly), 8) itching, and 8) yellowing of the skin and eyes (jaundice). Owing to public health concern, it is important to analyze the AFB1 concentration in edible animal products such as liver, meat, eggs, and milk.

It was evident from the present study that the residue of AFB1 in the liver of birds fed all treatment diets was not detected, which was coherent with the reslt reported by Hussain et al. (2016). However, this result was in contrast with the result reported by Moran et al. (2013) who observed the aflatoxin residues 27 or $145 \mathrm{ng} /$ $\mathrm{kg}$ in the liver of birds fed diets containing 10 or $50 \mathrm{ppb}$ AFB1 without mycosorb, respectively. The authors also reported that aflatoxin residues in the liver of experimental bird were reduced by $50 \%$ by the addition of my- 
cosorb $^{\circledR}$. Magnoli et al. (2011) claimed that the aflatoxin residues ( 0.15 to $1.2 \mathrm{ng} / \mathrm{g}$ ) were still able to be detected in the liver sample of birds fed diets containing a low level (50 ppb) of aflatoxin B1 (with and without a toxin binder). Previous studies (Resanovic \& Sinovec, 2006; Yang et al., 2012) also reported liver residues of $0.63 \mathrm{ppb}$ and $0.049 \mathrm{ppb}$ AFB1 in broilers (42 d) offered $44.5 \mathrm{ppb}$ and $69.3 \mathrm{ppb}$ AFB1, respectively. The differences were probably due to the differences in the type of aflatoxins used (pure vs natural aflatoxin), the sensitivity of individual bird in the assay, the duration of administration, the aflatoxin B1 concentration, and the type of equipment used to measure the concentration of aflatoxins.

The present result shows undetectable AFB1 residue in broiler breast meat which were exposed to low level of AFB1 ( $\leq 61.06 \mathrm{ppb}$ )-diets supplemented with mycosorb for 35 days. The result was in agreement with the report of Hussain et al. (2016) who recorded the absence of AFB1 residue in broiler muscle after 28days- feeding of a low level of AFB1 diet (50 ppb and $100 \mathrm{ppb})$. Conversely, the authors discovered the AFB1 residue above the permitted level $(>2 \mathrm{ng} / \mathrm{g})$ in the muscle of birds fed $400 \mathrm{ppb}$ and $800 \mathrm{ppb}$ of AFB1. One contrary study reported breast muscle residues of 0.015 ppb AFB1 in broilers offered 36.9 ppb and 69.3 ppb during 42 days experimental period (Yang et al., 2012).

The overall findings of the present work suggest that mycosorb, to a certain level, can be used as a toxin binder in practical broiler diets due to its beneficial effect on feed efficiency, especially in diets contaminated with AFB1<61.06 ppb. The significant effect of mycosorb in feed efficiency of birds fed the highest AFB1 contaminated diet $(61.06 \mathrm{ppb})$ might be achieved by increasing the inclusion level of mycosorb ( $>0.075 \mathrm{~kg} /$ ton diets).

It was also demonstrated that the lack of improvement in growth performance of birds fed AFB1 diets with mycosorb was closely related to the unchanged nutrient digestibility (Table 3), and the consistencies in the relative weight of selected internal organs (Table 4) of birds fed AFB1 diets added with mycosorb. The histopathological examination has shown that mycosorb did not change the villi condition in duodenum and jejunum of birds fed AFB1 diets with mycosorb. The villi condition of birds given AFB1 contaminated diets without mycosorb is still normal enough to support the nutrient digestion and absorption in the small intestine of birds. The addition of mycosorb still did not change the villi's condition and nutrient digestibility. Therefore, further study needs to be conducted to evaluate the higher inclusion level of mycosorb in afla-treated diets.

The undetected residue of AFB1 in liver of breast meat in the present study was probably due to the equipment used (LC-MS). The AFB1 residue might be detected by using a more sophisticated tool such as High-Performance Liquid Chromatography. The limit detection of AFB1 residue analysis in each type of equipment is different.

Even though the present study proves that no residue detected in liver and breast of birds fed low level of AFB1 diet without mycosorb, the addition of mycosorb or other toxin binders in commercial diets are still needed to reduce or eliminate the undetected residue of mycotoxin which might be present in the commercial diets. In addition, this study has proven that the addition of mycosorb in uncontaminated diets improves the feed per gain. Further study is needed to evaluate the response of birds fed AFB1 diets (low and high) added with mycosorb in different graded inclusion levels.

\section{CONCLUSION}

The AFB1 inclusion in broiler diets reduced crude fat digestibility and enlarged live size, but it did not affect growth performance, almost all internal organ size, intestinal histopathology, and meat quality. The detrimental effect of AFB1 in feed efficiency could be ameliorated by mycosorb. The AFB1 residue was not detectable in the liver, and breast meat of birds fed all treatment diets.

\section{CONFLICT OF INTEREST}

The authors declare that there are no any contradictory interests regarding financial, personal, or other relationships with other people or organization related to the present work discussed in the manuscript.

\section{ACKNOWLEDGEMENT}

The authors would like to thank the Ministry of Research, Technology, and Higher Education of Republic of Indonesia for providing funding for this research. We also thank Alltech Ltd distributor in Indonesia for its in-kind contribution for this research. The valuable assistance of Oktoforus Fahik, Marsianus Keli, Santi Ambarwati, Christine Flynn, and Julie Forman are fully appreciated.

\section{REFERENCES}

Abbasi F., J. Liu, H. Zhang, X. Shen, \& X. Luo. 2018. Effects of feeding corn naturally contaminated with aflatoxin on growth performance, apparent ileal digestibility, serum hormones levels and gene expression of $\mathrm{Na}+, \mathrm{K}+$-ATPase in ducklings. Asian-Australas. J. Anim. Sci. 31:91-97. https://doi.org/10.5713/ajas.17.0383

Afzal, M. \& S. Zahid. 2004. Effects of additional mycotoxin detoxifier in poultry feed containing different levels of aflatoxins on the performance of broilers. Asian-Aust. J. Anim. Sci. 17:990-994. https://doi.org/10.5713/ajas.2004.990

Aly, S. A. \& W. Anwer. 2009. Effect of Naturally Contaminated Feed with Aflatoxins on Performance of Laying Hens and the Carryover of Aflatoxin B Residues in Table Eggs. Pakistan J. Nut. 8: 181-186. https://doi.org/10.3923/ pjn.2009.181.186

AOAC. 2005. Official Methods of Analysis of AOAC International. 18th ed. Assoc. Off. Anal. Chem., Arlington.

Azeem, N., M. Nawaz, A. A. Anjum, S. Saeed, S. Sana, A. Mustafa, \& M. R. Yousuf. 2019. Activity and AntiAflatoxigenic Effect of Indigenously Characterized Probiotic Lactobacilli against Aspergillus flavus-A Common Poultry Feed Contaminant. Animals. 9:166. https://doi. org/10.3390/ani9040166

Barati, M., M. Chamani, S. N. Mousavi, S. A. Hoseini, M. T. A. Ebrahimi. 2017. Effects of biological and mineral compounds in aflatoxin-contaminated diets on blood parameters and immune response of broiler chickens. J. App. 
Anim. Res. 46:707-713. https://doi.org/10.1080/09712119.2 017.1388243

Benkerroum, N. 2020. Chronic and acute toxicities of aflatoxins: mechanisms of action. Int. J. Environ. Res. Public Health.17:423. https://doi.org/10.3390/ijerph17020423

Bryden, W. L. 2012. Mycotoxin Contamination of the Feed Supply Chain : Implications for Animal Productivity and Feed Security. Anim. Feed. Sci. Tech. 173:134-138. https:// doi.org/10.1016/j.anifeedsci.2011.12.014

Campos-M M. \& R. Campos-C. 2017. Application of quartering method in soils and foods. Int. J. Eng. Res. App. 7:35-39. https://doi.org/10.9790/9622-0701023539

Carvajal-Moreno A. 2015. Metabolic changes of aflatoxin B1 to become an active carcinogen and the control of this toxin. Immunome. Res. 11:2 https://doi. org/10.4172/1745-7580.10000104

Chu, Y., H.I Yang, Hui-Chen Wu, J. Liu, L. Wang, S. Lu, M. Lee, C. Jen, S. You, R. M. Santella, \& C. Chen. 2017. Aflatoxin $\mathrm{B} 1$ exposure increases the risk of cirrhosis and hepatocellular carcinoma in chronic hepatitis B virus carriers. Int. J. Cancer. 141: 711-720. https://doi.org/10.1002/ijc.30782

Diaz, G. J. \& H. W. Murcia. 2011. Biotransformation of Aflatoxin B1 and Its Relationship with The Differential Toxicological Response to Aflatoxin in Commercial Poultry Species. In Aflatoxins: Biochem. Mol. Biol. p. 3-20.

Fani Makki, O., N. Afzali, \& A. Omidi. 2013. Effect of different levels of Silymarin (Silybum marianum) on growth rate, carcass variables and liver morphology of broiler chickens contaminated with aflatoxin B1. Poult. Sci. J. 1: 105-116.

Feng, G. D., J. He, X. Ao, \& D. W. Chen. 2017. Effects of maize naturally contaminated with aflatoxin B1 on growth performance, intestinal morphology, and digestive physiology in ducks. Poult. Sci. 96:1948-1955. https://doi. org/10.3382/ps/pew420

Fouad, A. M., D. Ruan, H. K. El-Senonseuj, W. Chen, S. Jiang, \& C. Zheng. 2019. Harmful effects and control strategies of aflatoxin B1 produced by Aspergillus flavus and Aspergillus parasiticus strains on poultry: review. Toxins. 11:176. https://doi.org/10.3390/toxins11030176

Galarza-Seeber, R., J. D. Latorre, L. R. Bielke, V. A. Kuttappan, A. D. Wolfenden, X. Hernandez-Velasco, R. MerinoGuzman, J. L. Vicente, A. Donoghue, D. Cross, B. M. Hargis, \& G. Tellez. 2016. Leaky gut and mycotoxins: Aflatoxin B1 does not increase gut permeability in broiler chickens. Front. Vet. Sci. 3:10. https://doi.org/10.3389/ fvets.2016.00010

Garcia-Moraleja, A., G. Front, J. Manes, \& E. Ferrer. 2015. Development of a new method for the simultaneous determination of 21 mycotoxins in coffee beverages by liquid chromatography tandem mass spectrometry. Food Res. Int. 72:247-255. https://doi.org/10.1016/j.foodres.2015.02.030

Girish, C. K \& G. Devegowda. 2006. Efficacy of glucomannancontaining yeast product (mycosorb ${ }^{\circledR}$ ) and hydrated sodium calcium aluminosilicate in preventing the individual and combined toxicity of aflatoxin and T2-toxin in commercial broilers. Asian-Aust. J. Anim. Sci. 19:877-883. https://doi.org/10.5713/ajas.2006.877

Goodarzi, E, F. Ghoratt, A. M. Jerrahi, H. A. Adinehs, M. Sohrabivafa, \& Z. Khazaei. 2018. Global incidence and mortality of liver cancers and its relationship with the human development index (HDI): an ecology study in 2018. World Cancer Res. J. 6:e1255.

Grenier, B. \& T. J. Applegate. 2013. Modulation of Intestinal Functions Following Mycotoxin Ingestion: Meta-Analysis of Published Experiments in Animals. Toxins. 5:396-430. https://doi.org/10.3390/toxins5020396

Han, X.Y., H. Qi-Chun, L. Wei-Fen, J. Jun-Fang, \& X. Rong. 2008. Changes in growth performance, digestive enzyme activities and nutrient digestibility of cherry valley ducks in response to aflatoxin B1 levels. Livest. Sci. 119:216-220. https://doi.org/10.1016/j.livsci.2008.04.006

Hussain, Z., H. Rehman, S. Manzoor, S. Tahir, \& M. Muchtar. 2016. Determination of liver and muscle aflatoxin B1 residues and select serum chemistry variables during chronic aflatoxicosis in broiler chickens. Vet. Clin. Pathol. 45:330334. https://doi.org/10.1111/vcp.12336

Jettanajit, A. \& T. Nhujak. 2016. Determination of mycotoxins in brown rice using QuEChERS sample preparation and UHPLC-MS-MS. J. Chromatogr. Sci. 54: 720-729. https:// doi.org/10.1093/chromsci/bmv244

Kumar, R. \& C. Balachandran. 2009. Histopathological changes in broiler chickens fed aflatoxin and cyclopiazonic acid. Vet. Archiv. 79:31-40.

Kurniasih \& Y. A. Prakoso. 2019. Recent update: effects of aflatoxin in broiler chickens. J. World's Poult. Res. 9:68-77. https://doi.org/10.36380/jwpr.2019.8

Latimer, G. W. 2005. AOAC International. Official methods of analysis of AOAC International. 19 th $^{\text {th }}$ ed. Gaithersburg, MD: AOAC International.

Liu, N., J. Wang, Q. Deng, K. Gu, \& J. Wang. 2018. Detoxification of aflatoxin B1 by lactic acid bacteria and hydrated sodium calcium aluminosilicate in broiler chickens. Livest. Sci. 208:28-32. https://doi.org/10.1016/j.livsci.2017.12.005

Magnoli, A. P., M. P. Monge, R. D. Miazzo, L. R. Cavaglieri, C. E. Magnoli, C. I. Merkis, A. L. Cristofolini, A. M. Dalcero, \& S. M. Chiacchiera. 2011. Effect of low level of aflatoxin B1 on performance, biochemical parameters and aflatoxin B1 in broiler liver tissues in the presence of monensin and sodium bentonite. Poult. Sci. 90:48-58. https://doi. org/10.3382/ps.2010-00971

Marchioro, A. A., A. O. Mallmann, A. Diel, P. Dilkin, R. H. Rauber, F. J. H Blazquez, \& C. M. G. A. Oliveira. 2013. Effects of Aflatoxins on Performance and Exocrine Pancreas of Broiler Chickens Effects of Aflatoxins on Performance and Exocrine Pancreas of Broiler Chickens. American Assoc. Avian Path. 57:280-284. https://doi. org/10.1637/10426-101712-Reg.1

Matur, E., E. Ergul, I. Akyazi, E. Eraslan, \& Z. T. Cirakli. 2010. The effects of Saccharomyces cerevisiae extract on the weight of some organs, liver, and pancreatic digestive enzyme activity in breeder hens fed diets contaminated with aflatoxins. Poult. Sci. 89:2213-20. https://doi.org/10.3382/ ps.2010-00821

McDonald. P., R. A. Edwards. J. F. D. Greenhalgh, \& C. A. Morgan. 2002. Animal Nutrition. $6^{\text {th }}$ ed. Prentice Hall, United Kingdom.

Mogadam, N. \& A. Azizpour. 2011. Ameliorative effect of glucomannan-containing yeast products (Mycosorb) and sodium bentonite on performance and antibody titers against Newcastle disease in broilers during chronic aflatoxicosis. African J. Biotech. 10:17372-17378. https://doi. org/10.5897/AJB11.238

Moran, C. A, J. Apalajahti, A. Yiannikouris, S. Ojanpera, \& H. Kettunen. 2013. Effects of low dietary aflatoxin B1 on broiler liver concentration without and with mycosorb $₫$ toxin binder. J. Appl. Anim. Nut. 2:1-3. https://doi.org/10.1017/ jan.2013.11

Nalle, C. L., V. Ravindran, \& G. Ravindran. 2010. Nutritional value of faba beans (Vicia faba L.) for broilers: Apparent metabolisable energy, ileal amino acid digestibility and production performance. Anim. Feed Sci. Tech. 156:104111. https://doi.org/10.1016/j.anifeedsci.2010.01.010

Nalle, C. L, V. Ravindran V, \& G. Ravindran. 2011. Nutritional Value of Narrow-Leafed Lupin (Lupinus angustifolius) for Broilers. Br. Poult. Sci. 2:775-81. https://doi.org/10.1080/00 071668.2011.639343

Nalle, C. L., A. H. Angi, M. A. J. Supit, \& S Ambarwati. 2019. Aflatoxin and ochratoxin A contamination in corn grains 
and sago (putak meal) from different sources for poultry in West Timor, Indonesia. Int. J. Poult. Sci. 18:353-360. https:// doi.org/10.3923/ijps.2019.353.360

Nazarizadeh, H. \& J. Pourreza. 2019. Evaluation of three mycotoxin binders to prevent the adverse effects of aflatoxin B1 in growing broilers. J. Appl. Anim. Res. 47:135-139. https:// doi.org/10.1080/09712119.2019.1584106

Ortatatli, M., H. Oguz, F. Hatipoglu, \& M. Karaman. 2005. Evaluation of pathological changes in broilers during chronic aflatoxin (50 and $100 \mathrm{ppb}$ ) and clinoptilolite exposure. J. Res. Vet. Sci. 78:61-68. https://doi.org/10.1016/j. rvsc.2004.06.006

Peng, X., S. Bai, X. Ding, \& K. Zhang. 2017. Pathological impairment, cell cycle arrest and apoptosis of thymus and bursa of fabricius induced by aflatoxin-contaminated corn in Broilers. Int. J. Environ. Res. Public Health. 14:77. https:// doi.org/10.1080/03079457.2015.1023179

Resanovic, R. \& Z. Sinovec. 2006. Effects of limited feeding of AFB1 contaminated feed on the performance of broilers. Mycotoxin Res. 22:183-188. https://doi.org/10.1007/ BF02959274

Rotimi, O. A., S. O. Rotimi, J. M. Goodrich, I. B. Adelani, E. Agbonihale, \& G. Talabi. 2019. Time-course effects of acute aflatoxin B1 exposure on hepatic mitochondrial lipids and oxidative stress in rats. Front. Pharmacol. 10:467. https://doi.org/10.3389/fphar.2019.00467

Rotimi, O. A., S. O. Rotimi, C. U. Duru, O. J. Ebebeinwe, A. O. Abiodun, B. O. Oyeniyi, F. A. Faduyile. 2017. Acute aflatoxin B1-Induced hepatotoxicity alters gene expression and disrupts lipid and lipoprotein metabolism in rats. Tox. Rep. 4:408-414. https://doi.org/ 10.1016/j.toxrep.2017.07.006

Rushing, B. R. \& M. I. Selim. 2018. Aflatoxin B1: a review on metabolism, toxicity, occurrence in food, occupational exposure, and detoxification methods. Food Chem. Toxicol. 124, 81-100. https://doi.org/ 10.1016/j.fct.2018.11.047

Saki, A., A. Rahmani A, H. Mahmoudi, H. M. M. Tabatabaei, P. Zamani, \& A. R. Khosravi. 2018. The ameliorative effect of mycosorb in aflatoxin contaminated diet of broiler chickens. J. Livest. Sci. Tech. 6:39-47.

Solis-Cruz, B., D. Hernandez-Patlan, V. M. Petrone, K. P. Pontin, J. D. Latorre, E. Beyssac, X. Hernandez-Velasco, R. Merino-Guzman, C. Owens, B. M. Hargis, R. LopezArellano, \& G. Tellez-Isaias. 2019. Evaluation of cellulosic polymers and curcumin to reduce Aflatoxin B1 toxic effects on performance, biochemical, and immunological parameters of broiler chickens. Toxins. 11:121. https://doi. org/10.3390/toxins11020121

SAS Institute. SAS/STAT® User's Guide: Statistics. (SAS® University Edition- Free Online Software). SAS Institute Inc., Cary, NC, USA. https://www.sas.com/en_id/software/university-edition.html

Sineque, A. R., C. L. Macuamule, \& F. R. Dos Anjos. 2017. Aflatoxin B1 Contamination in Chicken Livers and Gizzards from Industrial and Small Abattoirs, Measured by ELISA Technique in Maputo, Mozambique. Int. J. Environ. Res. Public Health. 14:951. https://doi.org/10.3390/ ijerph14090951

Saleemi, M. K., K. Ashraf, S. T. Gula, M. N. Naseema, M. S. Sajid, M. Mohsin, C. He, M. Zubair, \& A. Khan. 2020. Toxicopathological effects of feeding aflatoxins B1 in broilers and its amelioration with indigenous mycotoxin binder. Ecotox. Env. Safety. 187: 109932. https://doi. org/10.1016/j.ecoenv.2019.109712

Suganthi, R. U., K. P. Suresh, \& R. Parvatham. 2011. Effect of aflatoxin on feed conversion ratio in broilers. J. Anim. Sci. 24:1757-1762. https://doi.org/10.5713/ajas.2011.11124

The American Cancer Society. 2019. Liver Cancer Early Detection, Diagnosis, and Staging. https://www.cancer. org/content/dam/CRC/PDF/Public/8700.00.pdf . [9 July 2020]

Wade, M. R., D. Sapcota, \& U. Verma. 2017. Ameliorating aflatoxicosis in commercial broiler chickens by dietary Mycosorb: Haemato-Biochemical studies. Indian J. Anim. Res. B 3182: 1-5. https://doi.org/10.18805/ijar.B-3182

Wade, M. R. \& D. Sapcota. 2015. Aflatoxicosis in broiler chickens, ameliorating with mycosorb : a review. Int. J. Curr. Res. 7:17487-17490.

Wu, Hui-Chen \& R. Santella. 2012. The role of aflatoxins in hepatocellular carcinoma. Hepat Mon. 12:e7238. https://doi. org/10.5812/hepatmon.7238

Yang, J., F. Bai, K. Zhang, X. Lv, S. Bai, L. Zhao, X. Peng, X. Ding, Y. Li, J. Zhang. 2012. Effects of feeding corn naturally contaminated with AFB1 and AFB2 on performance and aflatoxin residue in broilers. Czech J. Anim. Sci. 57:506-515. https://doi.org/10.17221/6383-CJAS

Yunus, A. W., E. Razzazi_Fazeli, \& J. Bohm. 2011. Aflatoxin B1 affecting broiler's performance, immunity and gastrointestinal tracts: a review of history and contemporary issues. Toxins. 3:566-590. https://doi.org/10.3390/toxins3060566 